DOI: 10.1515/ausfm-2016-0013

\title{
The Intermedial and the Transmedial across Samuel Beckett's Artistic Practices
}

\author{
Aténé Mendelyté \\ Lund University (Sweden) \\ E-mail: atene.mendelyte@litt.lu.se
}

\begin{abstract}
The essay offers a brief overview of famous Irish playwright Samuel Beckett's intermedial practices. By exploring a number of artistic media (drama, theatre, novel, television play, film) the artist tried to get at the essentials of each medium by virtue of his minimalist and mediaconscious aesthetics. As a result of this gesture he uncovered certain transmedial properties such as musical rhythm and structure, montage, black and white film and photography aesthetics and tenebrism situated at the core of supposed media-specificity. Moreover, it is argued that Beckettian intermediality has a pronounced meta-referential dimension as defined by Werner Wolf. Most, if not all, of Beckett's artworks include a medial selfreference of sorts such as the comment on the disembodiment of speech in radio plays or on the formative powers of lighting in theatre and film. What they also do is make the spectator aware of the fact of mediation and of what it entails. Therefore, the essay ultimately aims to show the immense significance of Beckett to intermediality studies not simply as an artist and a case study but as a media and intermediality theorist as well.
\end{abstract}

Keywords: intermediality, transmediality, meta-reference, medial selfreflexivity, Samuel Beckett.

Samuel Beckett's works are essentially and profoundly intermedial. Not only do they belong to various media (theatre plays, radio plays, television plays, novels, and a film) or incorporate various media (i.e. are multi-media artworks) but they also exemplify the deep form of intermediality: they adapt the established techniques of one medium to the context of another medium. In doing so, they address the very nature of mediation and intermediality. According to intermediality theorist Jürgen Müller, "a medial product becomes intermedial, when it transfers the multi-medial togetherness (Nebeneinander) of medial citations and elements to a conceptional cooperation (Miteinander)" (1996, 83). This transcendent medial gesture is precisely what takes place in 
Beckett's artistic practices and in this essay I will try to shed some light on just how that happens.

Beckett adapted various techniques and properties of music, painting, and photography in his theatre pieces not in a sense of mere intermedial quotation or reference but in a sense of a true conversion of a specific technique of one medium to another medium. In the words of Beckett's biographer James Knowlson, "Beckett showed, throughout his career, an exceptional ability (and a readiness) to transfer ideas and techniques from one medium to another, ostensibly quite different one, rethinking them, sometimes very radically, to test and stretch the boundaries of the new medium" (Haynes and Knowlson 2003, 126). Thus, the reflexive nature of Beckett's intermediality may also be understood as the reflexivity inherent in his very art and aesthetics; the artist experimented with the limits of each medium he worked with, implicitly redefining their relationships in his artworks.

This tendency to stretch the boundaries of the medium in question resulted in the fact that Beckett's works are not only self-referential but meta-referential as well in that they address the problems of the very medium they exemplify. This is clearly observable in Beckett's radio plays. For instance, Words and Music's dramatic conflict arises between the disembodied words and music, both vocal and sound properties freed from any embodiment, from any containment, which, consequently, refers to the very medium of radio and how it fragments the body and decenters the subject. Correspondingly, in theatre and television lighting plays a key role and is likewise able to fragment the body (as in Not I, That Time, What Where among others). Or, in an even more complex manner, lighting is able to correlate with the light of perception, of which examples are abundant throughout Beckett's theatre and television plays, but is especially clear in Play, which comments on the medium's dependence on light and its formative powers. The three characters are sitting inside separate urns; only their heads are visible. They are able to speak and continue their stories when the beam of light falls on them. The light continues to wander from one character to another and, therefore, their stories get periodically interrupted. Illumination in this case means being perceptible, emerging out of the darkness of invisibility and non-being. It, too, entails a becoming conscious of one's being perceived and a situation of being forced to perform for the spectator. These implications of such a bodily fragmentation address the cinematic medium as well, and in this specific sense one can even say that Beckettian theatre is cinematic.

Literary scholar Angela Moorjani observes along similar lines that "[t]he resistance to the light and to the camera-eye that the protagonists of Play and 
Film display serves to interrogate the power of the spectators' gaze as structured through the technology of each medium" (Moorjani 2008, 125). Film (1964) is the only film Beckett ever made, and much like Play, indeed, it deals with perceiving, being perceived and being mediated. The film's protagonist $\mathrm{O}$ (standing for object), played by the famous Buster Keaton, tries to escape any kind of perception. First he tries to hide from the perception of the people on the street, then from the other animate creatures in his room (a cat and a dog) and, finally, even from being perceived by such inanimate objects as the painting on the wall. Yet, ultimately, he cannot escape self-perception and in the end he comes face to face with himself - an encounter that becomes the source of immense horror. O cannot escape the spectators' perception either and thus by simply viewing the film one becomes O's torturer. Being mediated by someone's - including one's own - perception is shown to be an essential and terrifying quality of existence. The inescapable mediation and subject structuring in these and many other instances is brought into attention thematically as well as stylistically, which encourages the spectators to become self-aware and self-observant: the spectacle becomes self-conscious; our relationship to media becomes the central focus of perception. This phenomenon is known in the academic discourse of intermediality as meta-referentiality.

Meta-reference is an important concept in intermediality studies. Intermediality theorist Werner Wolf describes the term by emphasizing its theoretical potential: "metareferentiality can be said to denote all kinds of references to, or comments on, aspects of a medial artefact, a medium or the media in general that issue from a logically higher 'meta-level' within a given artefact and elicits corresponding self-referential reflections in the recipient” (Wolf 2009, v). "'Metaization,' correspondingly, is the movement from a first cognitive, referential or communicative level to a higher one on which first level phenomena selfreflexively become objects of reflection, reference and communication in their own right." (Wolf 2011, iv-vi.) Meta-reference encompasses both hetero- and self-reference. Thus, this concept describes the ability of artworks to comment on their own or other media and argues that artistic practices can be theoretical as well as reflexive. For instance, in Film one witnesses the metaization of film perception; the film perceives and is perceived by itself, as it were. Beckett is a meta-referential artist par exellence, commenting not only on the media of theatre, film, radio, but most importantly on language, and perception itself. As Beckett succinctly put it himself, he was "an analyzer. [He took] away all the accidentals because [he wanted] to come down to the bedrock of the essentials, the archetypal" (quoted in Knowlson and Knowlson 2006, 47). 
Therefore, there appears to be a high degree of minimalism in every type of media artwork of Beckett. They are all analysed and reduced to their bare essentials. This is the well-known principle of Michelangelo, whose art Beckett admired. Michelangelo believed that the stone itself already had its form and shape locked within it and the work of the sculptor was to set that form free; from this perspective, the artist is seen not as a multiplier but as a subtractor, an unveiler.

However, Beckett's meta-referential capacity is not limited to the distillation of a media essence such as disembodied sound in radio or the creative force of light in theatre and film. Another significant gesture is to uncover the transmediality of certain presumably media-specific techniques. One of such techniques creatively employed by Beckett was the Eisensteinian theory of montage (film editing): "[s]everal of Beckett's other plays use the principle of inter-cutting (either auditory or visual or a mixture of both) in a variety of ways. The most striking of these is That Time, which inter-cuts three different voice tracks relating to different periods in the life history of the protagonist. Again, within the three stories, different moments from the character's past are edited so as to balance or contrast one with another" (Haynes and Knowlson 2003, 120). The principle of montage thus not only helps to create a contrast between separate scenes, actions, or memories but also creates a link between them; it turns into a way of creating connections between different sonic images, i.e. sounds that imply images. Other outstanding examples thereof are the audiotape recordings that punctuate the rhythm of Krapp's Last Tape or the returning cut-up sonic images of Not I. The juxtaposition is meant to perceptually reconnect the images so that a different whole would be grasped. The meaning effect is this way created not only by what is explicitly told and does not purely reside in the stories that the characters cannot stop reciting. The meaning is lodged in what is cut out, omitted, deemed insignificant as well as in the very junctures and the acts of splicing together these memory shards.

Due to Beckett's treatment of montage, this becomes not only the cinematic technique of combining filmic images but the theatrical technique of combining sonic and memory images; it turns into the main means of constructing the theatrical character as a subject, signifying his or her experience in a subjective way - a theatrical equivalent of internal focalization in film. For example, in That Time the inter-cutting between the three voices from the protagonist's different stages of life (a young boy, a young man, and an old man) creates more than just a contrast between these stages. The same recurring memories and symbols reappear throughout these different ages and, as the play progresses, the different voices lose their distinction and start to merge. The protagonist's identity comes 
to be constituted as rhizomatic, as a branching bundle of roots curled around a few central nuclei. Here, montage reveals the change of identity through time as well as the timeless elements that resist that change.

Beckett's fascination with Sergei Eisenstein's theories relates to the latter's similar synaesthetic conception of art. The Russian theorist differentiated between “'metric montage' (an editing pattern based on the number of frames per shot), 'rhythmic montage' (maintaining continuity between shots), 'tonal montage' (creating an emotional effect on the part of the spectator), 'overtonal montage' (a combination of metric, rhythmic and tonal effects), and intellectual montage (soliciting an intellectual response from the spectator)" (Chapman 2013, 37). He saw some basic properties that were common to various art forms; hence the musical vocabulary. Correspondingly, Beckett understood his theatrical works in terms of musical compositions, which was not simply a metaphorical rendering of the pieces but their main structural feature. For example, to Happy Days the dramatist referred to as a "sonata for voice and movement" (Whitelaw 1996, 151); he indicated that Footfalls should "have a quality of a lullaby" (Whitelaw 1996, 151); and Beckett structured his play Play as a canon ${ }^{1}$ (Whitelaw 1996, 174). Also, "[w]hile Beckett was directing Footfalls at the Royal Court Theatre in London, he said to Rose Hill, who was playing the part of Mother: 'We are not doing this play realistically or psychologically, we are doing it musically.' This remark could be applied to all his productions. They were dominated by an idea that he had expressed in the early 1960s when he said: 'producers [i.e. directors - J. K.] don't seem to have any sense of form in movement, the kind of form one finds in music, for instance, where themes keep recurring. When, in a text, actions are repeated, they ought to be made unusual the first time, so that when they happen again - in exactly the same way - an audience will recognise them from before"” (Haynes and Knowlson 2003, 128). The essential dramatic conflict is inherent in music just like it is an essential feature of theatre or narrative in general. In a sonata, theme $\mathrm{A}$ is juxtaposed to theme $\mathrm{B}$, and then the themes are repeated, developed, and synthesized. The musical structure is itself dramatic and Beckett recognized this as a common feature of these different media and forms of artistic expression.

The impact of the musical structures was not supposed to be perceived entirely consciously since, after all, the quality of a lullaby is not the same thing as a lullaby. Rather, such musical structuring was supposed to affect the mind on a

1 Canon is the strictest version of the contrapuntal technique where one voice or melody has to follow and strictly imitate the quantity and quality of the previous interval. 
different, unconscious level, thus providing a deeper, multi-layered sensory and mental experience: " $[\mathrm{w}]$ hat is clear is that the author-director was deliberately adopting repeated patterns of moves, actions, gestures and sounds so that they would gradually infiltrate themselves into the unconscious of the spectator. Indeed, he [Beckett] described the process as being like 'the effect of those recurring images inserted into films for propaganda purposes which penetrate the subconscious by repetition'” (Haynes and Knowlson 2003, 137). This way, the spectator (even without consciously realizing) would experience the play musically and the experience would gain yet another, intermedial dimension. In his use of musical principles, Beckett wanted to affect both the conscious and the unconscious levels of perception of his spectators and aimed for the highest intensity of perception possible: subconscious and meta-reflexive.

One may ask how a subconscious phenomenon might lead to meta-reflexivity, which is by definition reflexive and, therefore, conscious. The rhythms present in movements, gestures, language and memory refrains, etc. unconsciously ingrain themselves in the minds of the spectators, and in doing so they make one conscious of the rhythmical nature of existence as well as the rhythms of the medium that refract that existence. For instance, Play's characters are stuck in a rut of their own personal melodrama - the inability of getting out of this situation is precisely signified by the repetitious rhythmicality of their performances. But the rhythmic alteration between illumination and darkness, too, brings to attention the power of theatre, film and television to make someone or something perceivable and to do so ad infinitum, irrespective of content - mediation itself is rhythmical.

Moreover, the dramatist's synaesthetic aim extended even further as he wrote to his friend Axel Kaun as early as 1937 that it should be possible to reduce "the terrible materiality of the word surface... like for example the sound surface, torn by enormous pauses, of Beethoven's seventh symphony [to - J. K.] a whisper of that final music or that silence that underlies all" (quoted in Haynes and Knowlson 2003,145 ). In other words, theatre - just like certain exceptional pieces of music should be able to signify the lack that hides behind any act of signification and thus momentarily break the chain of significations, exposing the holes of the symbolic structure through which the primordial darkness and chaos is seeping through. This ability is not limited to music but it has found its purest expression in this medium due to its close relationship to affect and to pure intensity. That is to say, music is able to radiate the intensity of signification without actually signifying anything. Beckett tried to adapt this ability in the form of certain subtle structural features such as montage and musical structures to another medium this way 
implying that such is the aim of all art: to give shape to the formless and by this very act to expose the formlessness of all form. For Beckett, this aim at "that silence that underlies all” is, in fact, a transmedial quality uniting all artistic media.

As mentioned earlier, meta-reflexivity involves recognizing a theoretical potential inherent in certain works of art. Here one is bound to wonder as to what kind of arguments are implicit in Beckett's practices. Even though Eisensteinian theory of montage has made an impact on Beckett's practices, ${ }^{2}$ Beckett's approach to film and to a certain degree theatre (both stage and television plays) is largely Arnheimian in that there are certain undeniable aesthetic correspondences between these two thinkers. In everything Beckett did he preferred the minimalist black and white aesthetics, which, as it happens, corresponds to Rudolf Arnheim's idea of cinema as art. Literary critic Matthijs Engelberts even sees Beckett's Film as a direct response to the 1930s film theory debate in which Arnheim was one of the main participants defending the independent artistic value of silent black and white films: "[i]t is therefore self-evident for Beckett that Film would be made in black and white; by the same token, it is beyond a doubt for Arnheim that color threatens the artistic character of cinema as much as sound does: 'What will the color film have to offer when it reaches technical perfection? We know what we shall lose artistically by abandoning the black-and-white film. Will color ever allow us to achieve a similar compositional precision, a similar independence of 'reality'? Beckett's Film constitutes a response, silent of course, to this rhetorical question of the 1930s" $(2008,156)$. Significantly, the film is not simply silent but it chooses to be silent in an era of the talkies, the sound films, which adds a whole new level of meaning to this aesthetic choice. In the words of the great existentialist philosopher Jean-Paul Sartre, "[s]ilence itself is defined in relationship to words, as the pause in music receives its meaning from the group of notes around it. This silence is a moment of language; being silent is not being dumb; it is to refuse to speak, and therefore to keep on speaking" $(1967,14)$. The silence of Beckett's film's is, likewise, a moment of meta-referential language; it keeps on speaking about the film medium with its silence.

Even more interesting from an intermedial perspective is that Arnheim's ideas on photography are truly resonant with Beckett's practice and treatment of theatre and film. A still photograph in a context of moving images is an established and explored intermedial configuration. But Beckett offers a much more unorthodox configuration by uniting theatre and still photography. In a piece on a still

2 Beckett even wished at a certain point in his career to study with Eisenstein and wrote a motivational letter to the Russian film-maker. 
photograph inserted in a movie Arnheim once wrote: "a still photograph inserted in the middle of a moving film gives a very curious sensation; chiefly because the speed with which time is passing in the moving shots is carried over to the still picture, whose effect therefore is similar to that produced by holding one expression for an uncomfortably long time. And just as the time is carried over, so the rigidity is, as it were felt as movement, that is suspension of movement" $(1933,110)$. The juxtaposition here is not so much between the material film stock and a piece of photograph but between the principles of the image with movement and the image without movement - not just the stillness of the image. Nowhere is the use of this technique as powerful as in Krapp's Last Tape when Krapp freezes while listening to the recordings of his previous selves and the whole scenic image turns into a still photograph inserted into a stage play. Because this theatrical freeze-frame is not narratively motivated, the effect is the suspension of movement and the result is the image without movement. This morphing of movement into the suspension of movement produces an alienating effect in the theatre image and shifts its temporality away from the immediacy of the present. Just like a still photograph inserted in a film (e.g. the last shot in Francois Truffaut's The 400 Blows [1959]) it gives way for the opening of a deeper dimension of reality. The narrative development is suddenly interrupted; an individual moment is extracted from the chain of events and made to turn inwards, to reflect back upon itself. This function of freezing movement is reminiscent of the significance an aria has in an opera; an aria stops the narrative development otherwise carried by recitative and expresses the innermost affects of the character. One is forced to encounter the depth of a moment, instead of focusing on what happens next. Music scholar John Butt goes so far as to suggest that aria, in contrast to recitative, introduces the subjective presence of time into a given opera: “[w]hile the recitative mode comes close to 'everyday' time consciousness in its flow of time seemingly pegged to the objective passing of time (conforming to the traditional 'unity' of time), the aria focuses more specifically on the phenomenon of time consciousness" $(2010,130)$. The combination of these two different, one objective, the other subjective, temporalities is another transmedial quality that opera and Beckett's combination of theatrical/cinematic and photographic principles share.

To create the visual effect of the photographic dimension, when staging Krapp's Last Tape Beckett took special care in making sure that every object on the stage was either black or white. This not only strengthened the Gnostic and Manichean themes of the play but also exemplified the black and white film and photography 
aesthetics. The instructions Beckett gave were blatantly clear: "[w]ith regard to costume it should be sufficiently clear from text (don't be afraid of exaggerating with boots). Black and white (both dirty), the whole piece being built up in one sense on this simple antithesis of which you will find echoes throughout the text (black ball, white nurse, black pram, Bianca, Kedar - anagram of 'dark' - Street, black storm, light of understanding, etc.) Black dictionary if you can and ledger. Similarly black and white set" (quoted in Harmon 1998, 60). Beckett's television play aesthetics also draws on the same conception of Arnheimian utilization of absence; Beckett demanded that the plays should be filmed in black and white because the dramatic effect of the plays depended on the contrast of these colours. In a visually minimalist masterpiece Ghost Trio (German SDR 1977 version, directed by Beckett) the playwright and now director of his own work went even further since the television play seems to be mostly played out in shades of grey - black and white being reduced to a single colour. The point of this experiment is to achieve maximum intensity with minimum extensity.

Thus, there is a profound correspondence between Arnheim's thoughts on cinema, i.e. his preference for black and white film aesthetics, and Beckett's own aesthetic vision. Arnheim conjectured that "the reduction of actual colour values to a one-dimensional grey series (ranging from pure white to dead black) is a welcome divergence from nature that renders possible the making of decorative pictures rich in intellectual significance by means of light and shade" (1933, 102-103). This "intellectual significance" was what mattered most to Beckett since it adds to the exclusively contemplative nature of the dramatist's oeuvre. These artworks do not obliterate language or thought; they just simply free them from the schematic automaton that every discourse cannot but eventually become and the habitus of thought and perception that it engenders. In order to achieve that, a divergence from the realism that natural colour brings with it is necessary. Therefore, black and white images pervade the dramatist's theatre, film, and television pieces as a transmedial property, exemplifying the usefulness of absence. Again, minimalism is the key as the artist subtracts, not multiplies phenomena; because in order to create a conflict one does not need much more than the contrast between black and white.

In addition to the aforementioned media, painting had a major influence and was remediated in Beckett's works in a number of ways as well. Of high significance are the $16^{\text {th }}$ - and $17^{\text {th }}$-century painting techniques of chiaroscuro and tenebrism. The latter was an exaggerated version of chiaroscuro - a painting technique that concentrates on the contrast between light and darkness, where 
religious scenes in particular were illuminated by an unnatural mysterious light source, often signifying God. Perhaps the most mystifying feature of this technique is its ability to convey a sense that the painted object is illuminated from within and is not lit by any outside light source. "Tenebrism is a Baroque style of painting in which the contrast of darkness and light introduces an element of mystery, ambiguity, and understatement, lending a dynamic quality to the light and bringing an element of drama and pathos." (Hortolà 2015, 37.) In tenebrism, more so than in chiaroscuro, what matters most is not the individual colours but the contrast between light and shadow. The exemplary tenebrism of Caravaggio emphasizes and brings to the foreground certain bodily features, dramatizes them to a remarkable effect and makes the body itself the locus of drama.

These techniques were reinterpreted in the dramatist's theatre, television and film pieces. Literary critic Enoch Brater also observes this correspondence: "[i]n the visual arts, too, Beckett was drawn to the precision of a Caravaggio, with his seamless control over light on canvas when less did not seem possible" (2007, 178). For example, the chiaroscuro and tenebrist principle may be observed in the performance of Play. When staging the performance, Beckett demanded that the urns in which the characters were supposed to sit be illuminated by a single source of light and everything else should remain in pitch-black darkness. Another remarkable instance thereof is the staging of Not $I$, in which the illumination is limited to a single bodily organ - a mouth. Even the exit signs - a constant defamiliarizing light presence in every theatre performance - are supposed to be switched off. Indeed, less does not seem possible. If one compares Beckettian illumination to the treatment of body in Caravaggio, one must conclude that Beckett presents an extreme version of tenebrism; by reducing illumination to the very minimum, he achieves the maximum of dramatic emphasis. Tenebrism is this way conceptually united with black and white film and photography aesthetics, and functions as yet another transmedial property in Beckett's art.

To conclude this all too brief overview, Beckett worked with a number of artistic media and in doing so he achieved a conceptual cooperation of the media he brought together. He reduced each medium to its essentials such as the interplay between light and dark, movement and stillness or the meaningful (not only structural) use of rhythm. He was able to adapt various aesthetic properties from one medium to another, thus showing the universality of certain artistic techniques and principles. Therefore, Beckett exhibited not only intermediality but was able to expose the transmediality at the very core of intermediality in his artistic practices. Beckett's intermedial practices, too, include a meta-referential 
dimension since they examine the nature and the limits of media and make the spectator aware of the event of mediation.

\section{References}

Arnheim, Rudolf. 1933. Film. London: Faber \& Faber.

Brater, Enoch. 2007. From Dada to Didi: Beckett and the Art of His Century. In Borderless Beckett, eds. Minako Okamuro et al., 173-186. New York, Amsterdam: Rodopi.

Butt, John. 2010. Bach's Dialogue with Modernity - Perspectives on the Passions. Cambridge: Cambridge University Press.

Chapman, James. 2013. Film and History. Basingstoke, New York: Palgrave Macmillan.

Engelberts, Matthijs. 2008. Film and Film: Beckett and Early Film Theory. In Beckett at 100 Revolving It All, eds. Linda Ben-Zvi and Angela Moorjani, 152165. Oxford: Oxford University Press.

Harmon, Maurice, ed. 1998. No Author Better Served: The Correspondence of Samuel Beckett and Alan Schneider. Cambridge, MA: Harvard University Press.

Haynes, John and James Knowlson. 2003. Images of Beckett. Cambridge: Cambridge University Press.

Hortolà, Policarp. 2015. The Aesthetics of Haemotaphonomy. Alicante: ECU.

Knowlson, James and Elizabeth Knowlson, eds. 2006. Beckett Remembering Remembering Beckett. London: Bloomsbury.

Moorjani, Angela. 2008. Ne(i)ther-World Icons, Elsheimer Nocturnes, and Other Simultaneities in Beckett's Play. In Beckett at 100 Revolving It All, eds. Linda Ben-Zvi and Angela Moorjani, 123-138. Oxford: Oxford University Press.

Müller, Jürgen. 1996. Intermedialität. Formen moderner kultureller Kommunikation. [Intermediality: Forms of Modern Cultural Communication] Münster: Nodus Publikationen.

Sartre, Jean-Paul. 1967. What Is Literature? London: Methuen.

Whitelaw, Billie. 1996. Billie Whitelaw...: Who He? New York: St. Martin's Press. Wolf, Werner, ed. 2009. Metareference across Media. Amsterdam, New York: Rodopi.

Wolf, Werner, ed. 2011. The Metareferential Turn in Contemporary Arts and Media. Amsterdam, New York: Rodopi. 